\title{
Treating Complicated Grief among Orphaned Children in Kenya: Effectiveness of Complicated Grief Therapy
}

\author{
Maureen 0. Ngesa, Sylvia Tuikong, Kennedy Ongaro \\ Department of Clinical Psychology, Daystar University, Nairobi, Kenya \\ Email: maureenaonyango@daystar.ac.ke
}

How to cite this paper: Ngesa, M. O., Tuikong, S., \& Ongaro, K. (2020). Treating Complicated Grief among Orphaned Children in Kenya: Effectiveness of Complicated Grief Therapy. Open Journal of Social Sciences, 8, 461-478.

https://doi.org/10.4236/jss.2020.84034

Received: February 19, 2020

Accepted: April 21, 2020

Published: April 24, 2020

Copyright (อ 2020 by author(s) and Scientific Research Publishing Inc. This work is licensed under the Creative Commons Attribution International License (CC BY 4.0).

http://creativecommons.org/licenses/by/4.0/

(c) (i) Open Access

\begin{abstract}
Complicated Grief (CG) also referred to as complicated bereavement is a clinically significant condition even though there is limited evidence on its prevalence and treatment in Kenya and Africa in general. The main aim of this 2019 study was to test the efficacy of a modified Complicated Grief Therapy (CGT) in treating complicated grief (CG) among orphaned children. A total of 426 orphaned children aged 10 - 15 years were screened using the Brief Grief Questionnaire to sample those with elevated grief scores. Of the 263 who met the criteria, only 241 participants fully participated in the six months study with 123 and 118 participants in the treatment and the control groups respectively. The treatment group was subjected to a shortened version of the CGT (12 weeks) while no treatment was offered to the control group. The prevalence of grief among orphaned children was $66 \%$ and using the Inventory for Complicated Grief, to determine the clinical levels, a mean grief score of $31.6(\mathrm{SD}=9.52)$ was recorded. The reduced version of CGT was effective in the reduction of complicated grief symptoms $\mathrm{t}(122)=-15.79, p<0.001$ at a weekly reduction of 1.29 points. In the case of the control group, the paired sample test showed a statistically insignificant reduction of CG score, $\mathrm{t}(117)=$ $-0.712, p=0.478$. Conclusions: Reducing CGT sessions 12 sessions to make it shorter and less stringent and using it as group therapy in a school setup did not interfere with its effect on the treatment of complicated grief among orphaned children.
\end{abstract}

\section{Keywords}

Complicated Grief, Orphaned Children, Complicated Grief Therapy, Bereaved Children, Parental Death 


\section{Introduction}

Death of a parent is considered the most devastating event for a child. Unfortunately, as adults negotiate their grief and move on with life, it is assumed that the bereaved child is not grieving and is not given much attention in the entire mourning process (Akerman \& Statham, 2014; Huyah, 2017). The high prevalence of orphanhood in Sub Saharan African (SSA) countries is directly related to high HIV and AIDS rates in these countries (Selamu \& Singhe, 2018). As of 2017, there were over 150 million orphaned children across the globe (SOS, 2017), with 8 out of every 10 orphans living in Sub-Saharan African countries (UNAIDS, 2018). Globally, over 12\% (approximately 17 million) of all orphans are AIDS orphans and this could be associated with recent global reports by UNAIDS (2018) indicating that on average, in 2017, 940,000 adults died from AIDS-related illnesses.

To improve care provision for orphans in Kenya, the government has attempted to put in place some policies. One such program is the Cash Transfer Program for Orphans and Vulnerable Children (CT-OVC) initiated in 2006 (State Department of Social Protection, 2011). The CT-OVC program has been geared mostly at ensuring that children are enrolled in school. This program also promotes kinship care with families (Handa et al., 2014). Other policy documents include 2014, the guideline for Alternative Family Care for Children in Kenya; and the updated National Directory for children's care published in 2015. The Department of Children Services, however, admitted in the 2015 report that even though the government had put in place policies on interventions of orphans and vulnerable children as a result of HIV and AIDS; "most of the interventions for these children have mainly focused on addressing their visible and pressing needs such as food, clothing, and shelter with little focus on the invisible needs among them psychosocial support" (Ministry of Labour Social Security and Services, Kenya \& Department of Children Services Kenya, 2015: p 1).

As global research on the implementation of psychosocial support for orphans continues, some authors have concluded that in order to scale up access to psychosocial care for orphans especially in HIV prone areas, school-based therapy interventions must be prioritized (Skeen et al., 2017). Mwoma and Pillay (2015) also opined that, since school-going children spend most of their time in school, the school is better placed to provide psychosocial support. Citing Richter et al., (2004), the authors stated that there was a need to train and equip teachers to offer psychosocial support for orphans and vulnerable children as a way to improve academic outcomes for OVC (Mwoma \& Pillay, 2015).

Despite these obvious psychosocial challenges with detrimental effects on the academic performance of the orphan, in Kenya, psychosocial care for orphans has remained secondary to the provision of economic necessities. Secondly, lack of mental health literacy coupled with limited and unaffordability of mental health services means that complicated grief among orphans may go undiagnosed. In addition, and despite existing research on the impact of grief on the 
socio-cognitive functioning of the bereaved child, in Kenya, there exists no structured grief work program that can be used by school counselors to treat complex bereavement in children faced with parental death.

To design and test such a manual in a Kenyan context, a collection of extensive data was needed to describe grief manifestations and risk factors that may be unique to orphans living in rural Kenya. The diverse environmental risk factors unique to such orphans are not only an impediment to treatment using western treatment manuals but can be a point of learning to design and modify treatment manuals that are targeted for orphaned children in developing countries such as Kenya. Such programs have been found to be sustainable in countries with few resources and minimal capacity for counselors (Tol, Kemproe, Susanty, Jordans, Macy, \& De Jong, 2008).

It was against this background that this study evaluated the effectiveness of a Modified Complicated Grief Therapy (MCGT) as a grief work program for schools. MCGT was developed by shortening the current 16 sessions of CGT to a 12 session program by only selecting techniques that were less stringent to train to enhance their adaptability, affordability, and sustainability as a school-based grief management program for schools. The aim was to determine if such a program would be a sustainable means of providing psychological services to a large number of bereaved children in Kenya.

\section{Literature Review}

\subsection{Complicated Grief}

Complicated Grief (CG) also referred to as complicated bereavement is a clinically significant condition even though its existence has been overlooked until recently (Enez, 2018). The aspect and possible diagnosis of complicated grief was first done in 1995 by a research team led by Holly Prigerson (Enez, 2018). In their study, the team was initially interested in distinguishing symptoms that were distinct to complicated grief and that could clearly be differentiated from bereavement associated depression or distress (Prigerson, et al., 1995).

It has been estimated that about $7 \%-10 \%$ of the bereaved population will experience complicated grief (Kersting, Brähler, Glaesmer, \& Wagner, 2011). In his article on complicated grief, Enez (2018) approximates that at least $10 \%$ of bereaved individuals will develop complicated grief. Unfortunately, even though this prevalence may be considered low, in at-risk populations, the prevalence is much higher at $20 \%$, and $50 \%$, among close relatives/caregivers of patients with dementia and HIV patients and as high as $78 \%$ in violent deaths respectively (Papa et al., 2013).

In complicated bereavement, the process of adapting and accepting the finality of the death of a loved one is slowed and complicated in the sense that the individual is unable to readjust back to normal functioning (Simon, 2013). During the grieving process, the individual is expected to redefine their goals and restore a meaningful life that is satisfying without the deceased (Koon \& Neo, 2016). 
Just as in adults, children also go through a period of mourning and bereavement characterized by a significant grieving process (Akerman \& Statham, 2014). When this grief is not managed, children are at an increased risk of developing complicated grief disorders. A study done in the US in 2013 confirmed that children also presented with symptoms of complicated grief, (National Alliance for Grieving Children, as cited in Shear 2015). Among those included in the survey, $39 \%$ of children and adolescents reported to be having problems with sleep and $45 \%$ reported that they were having challenges concentrating in school. In addition, orphans were more likely to drop out of school, lack motivation and in the process record poor academic performance and low primary to secondary transition rates.

The psychological impact of losing a parent affects the child's ability to focus or remain motivated in school, and further heightening the possibility of reduced academic performance (Limo \& Kibowen 2017). The vulnerability is further heightened by environmental factors such as poverty, family situation, high dependence level, stigma and inadequate intervention strategies (World Orphans, 2018). These factors combined may further complicate the grieving process exposing the child to complex bereavement.

\subsection{Complicated Grief Therapy}

Shear (2005) CGT manual for complicated grief combines CBT techniques and elements of interpersonal psychotherapy for depression and is based on the Dual processing model of grief by Margaret Stroebe and Henk Schut in which the person grieving fluctuates between the loss and recovering from the loss (Stroebe \& Schut, 1999). CGT has been tested in various populations and has been found to be effective (Asukai, Tsuruta, \& Saito, 2011; Shear et al., 2014; Wetherell, 2012). However, one shortcoming about CGT therapy is an over-reliance on the CBT techniques and its prolonged treatment. Ideally, current CGT requires 16 sessions and additional sessions for parents and caregivers. Some sessions can last up to 25 individual sessions and are highly structured (Wetherell, 2012).

Although CGT has been proven to treat CG in children and adults, the recommended minimum of 16 sessions and need for specialized training to apply some of its techniques makes it unsuitable for adoption as a school-based intervention for orphaned children in rural Kenya. The current study, therefore, proposes a school based complicated grief therapy that has 12 sessions, is trainable and implementable by school counselors in managing complicated grief among children who have experienced parental death.

\section{Methodology}

This six month study commenced on May 2019 and was concluded in October 2019. The study sought to determine the effectiveness of the modified complicated grief therapy in the treatment of grief among orphaned children in rural Kenya. The study adopted a quasi-experimental research design with a pre and 
posttest. A total of 12 public schools were engaged in the study. The school headteachers provided a list of 766 orphaned children enrolled in their respective schools. From this list, only orphaned children aged 10 - 15 years and had lost a parent at least six months and not longer than two years at the time of commencement of this study were recruited to join the study. Based on these inclusion criteria 426 orphaned children qualified for screening and were screened for grief symptoms using the Brief grief Questionnaire. Out of the 426 screens, only 397 responses were considered valid giving a response rate of $93 \%$. From the screening, 263 participants out of the 397 had elevated grief scores (5 points and above in the BGQ) giving an indication of complex bereavement and placing the prevalence of complicated grief among orphaned children at $66 \%$.

To determine the clinical levels of grief in preparation for treatment, a baseline assessment using the inventory of complicated grief was done for the 263 who had elevated grief scores. Out of the 263 who met the criteria at screening, only 259 were present in the school at baseline assessment. The 259 were enrolled in the study and grouped into experimental and control groups. The experimental group $(\mathrm{n}=128)$ was enrolled for the 12-week intervention while the control group $(n=131)$ was not given any intervention. At the end of the intervention and at endline assessment only 241 participants were still in the study (experimental group $n=123$; control group- $n=118$ ). A total of 18 participants dropped out of the study due to school transfers and absenteeism during the weekly interventions.

\subsection{Participants}

The participants in this study were orphaned children aged 10 - 15 years and who had lost at least one parent through death. The participants were drawn from 12 public primary schools within Siaya County. In total, a sample size of 241 participants who remained in the study for the entire duration of the study was used for the analysis.

\subsection{Sampling Procedure}

In this study, a multistage sampling procedure was done. First cluster sampling was used to group the population-based on the geographical boundaries of Siaya county. In the second stage, purposive sampling was done in which a number of primary schools from each of the six sub-counties were identified based on the accessibility. In total, 12 schools were purposively chosen based on the accessibility and availability of a good enough targeted population to draw a sample. Purposive sampling was then used to identify children who had lost one or both parents at least six months before the commencement of the study. Finally, random sampling was used to group the schools into treatment and control groups.

The participants were first screened using the Brief Grief Questionnaire (BCQ) and only those who scored 5/10 (50\%) were prequalified for the study. The ones prequalified were then tested using the Inventory of Complicated Grief 
to determine the clinical levels of grief at baseline. The experimental group was subjected to 12 weeks of the shortened version of the complicated grief therapy. The following were the modifications done to the therapy to suit the context of the participants and make it suitable for group interventions.

The researcher argued that the current 16 session CGT therapy which requires that caregivers be engaged in the study may not be feasible especially for orphaned children in rural Kenya. Secondly, considering that the current model incorporates techniques that require intensive training, such training may not be accessible to many professionals in low-income areas such as Siaya county.

The MCGT manual proposed by the researcher is a 12 session program that can be administered as a group intervention. The effectiveness of MCGT as a school based intervention was tested. In deciding the sessions and techniques to remove, the researcher only considers techniques that can be implemented in a group session and also techniques that do not require intense expertise or training to administer. Table 1 shows the modifications made to the proposed MCGT.

\subsection{Ethical Considerations}

This study was approved by the Daystar Ethics Board, and the National Commission for Science Technology and Innovation (NACOSTI). Informed consent

Table 1. Differences between existing CGT and modified CGT used in the current study.

\begin{tabular}{|c|c|c|}
\hline Description & Current CGT & Proposed MCGT \\
\hline Total number of sessions & 16 & 12 \\
\hline \multirow{4}{*}{ Introductory Phase } & 3 sessions Session 1 - 3 & 2 sessions: Session $1-2$ \\
\hline & History taking, & History taking \\
\hline & Overview of CGT, & Psychoeducation on grief \\
\hline & Grief monitoring & Training on Grief monitoring \\
\hline \multirow{10}{*}{ Intermediate Phase } & & 6 sessions: Sessions $3-8$ \\
\hline & & Narrative of the death story \\
\hline & 7sessions: & Narrative of memories with the deceased \\
\hline & Sessions $4-10$ & Life changes after the death \\
\hline & Restoration work & Grief monitoring of thoughts/beliefs \\
\hline & Imaginal revisiting & Grief monitoring of emotions \\
\hline & Imaginal conversation & Grief monitoring of behaviors \\
\hline & Memory work & Psychoeducation on the relationship \\
\hline & Progress evaluation & between thoughts, emotions, and behaviors \\
\hline & & $\begin{array}{l}\text { Homework on alternative thinking, feeling, } \\
\text { and behavior }\end{array}$ \\
\hline \multirow{10}{*}{ Final Phase } & & 4 sessions: Sessions $9-12$ \\
\hline & 6 sessions: & Progress evaluation of thoughts, emotions, \\
\hline & Session $11-16$ & and behavior \\
\hline & Restoration work & Saying goodbye: an imaginal conversation \\
\hline & Imaginal revisiting & with deceased for closure \\
\hline & Imaginal conversation & Rebuilding new relationships \\
\hline & Memory work & Adaptive coping skills \\
\hline & Progress evaluation & Preparation for terminations \\
\hline & Preparation for termination & Evaluation of grief symptoms \\
\hline & & Review of participants after 3 months \\
\hline
\end{tabular}


was signed by the caregivers, and participants signed the informed assent forms. Participation in the study was voluntary and no participants were coerced to be in the study. Participants were also made aware that they could opt out of the study at any time of the study. No monetary benefit was accorded to participants.

\subsection{Data Collection Tools}

\section{Brief Grief Questionnaire}

The grief screening was done using the Brief Grief Questionnaire (BGQ) Items that make up the BGQ come from the proposed 5 criteria for Complicated Grief. They consist of 1) intrusive images of the deceased, 2) avoidance of reminders of the loss, 3) trouble accepting the death, 4) feeling numb and detached, and 5) overall interference with ongoing life. Respondents are asked to report the frequency $(0=$ not at all; $1=$ somewhat; $2=$ a lot $)$ of each item. A score of 5 or greater on the BGQ indicated the presence of complicated grief. The validity of the BGQ was found to be satisfactory with a Cronbach's alpha score of 0.75 and internal consistency of 0.39 when tested with the Japanese population (Ito, et al., 2012).

Inventory for Complicated Grief (Prigerson et al. 1995)

The ICG tool was used to determine the clinical levels of the grief symptoms. Data collected from the ICG was used to monitor the reduction of symptoms and analyzed to determine the efficacy of the intervention. ICG consists of 19 items whose responses are provided on a 5-point Likert scale to present the extent of severity. The scales have a score ranging from $0-4$ points; 0 -never, 1-seldom, 2-sometimes, 3-often and 4-always and has a maximum score $=76$ (Wagner \& Maercker, 2010). The 19 items in the ICG target six dimensions considered as critical in diagnosis for complicated grief (Solomon, 2015). The cut-off point for the ICG score is placed at 25 points.

\subsection{Data Analysis}

The participants' clinical grief scores for both control and treatment groups were recorded at baseline, the intervention was then administered for 12 weeks to the treatment group only. In the $12^{\text {th }}$ week, a second assessment was done for both treatment and control groups. No intervention was given after week 12. The participants in both groups were then tested again 12 weeks after the intervention was ended to determine the longevity of the effect of the treatment. To determine the effectiveness of MCGT in treating complicated grief, inferential analysis specifically, t-tests were used to test the difference in means, between the treatment and control group. The change monitored was based on the change of grief scores at the three timelines at week 1, week 12, and week 24 . The statistical significance was examined at a $p$-value of 0.05 . The effect size was calculated based on Cohen's $d$.

\section{Results}

Majority of participants were aged $10-11$ years (preteen) at 39.4\% ( $\mathrm{n}=95)$, and 
the gender distribution for the study sample was 123 males (51\%) and 118 females (49\%). Over half of the orphaned children in this study were paternal orphans (lost only a father) at $56.5 \%(\mathrm{n}=136)$ compared to the $24.1 \%(\mathrm{n}=58)$ who had lost only a mother, and $19.5 \%(\mathrm{n}=47)$ who had lost both parents. Majority of the participants were living with a relative $44.8 \%(\mathrm{n}=108)$ while only $2.1 \%(n=5)$ were living in a children's home. Specifically, it was found that most of the orphaned children were under the care of their grandparents at $65.5 \%$ (n $=79)$ while $7.4 \%(n=9)$ were living with older siblings. Finally, majority of the participants had lost their parents through illness at $74.2 \%(\mathrm{n}=179)$, while only $13.6 \%(n=33)$ lost their parents through accidents, and $12.2 \%(n=29)$ indicated they did not know the cause of death. The results are summarized in Table 2 .

Table 2. Sociodemographic characteristics.

\begin{tabular}{|c|c|c|c|}
\hline & & Count $(\mathrm{N})$ & Percentage (N \%) \\
\hline & $10-11$ (preteen) & 95 & $39.4 \%$ \\
\hline \multirow[t]{2}{*}{ Age Group } & $12-13$ (early teen) & 85 & $35 . .2 \%$ \\
\hline & $14-15$ (mid teen) & 61 & $25.3 \%$ \\
\hline \multirow[t]{2}{*}{ Gender } & Male & 123 & $50.1 \%$ \\
\hline & Female & 118 & $48.9 \%$ \\
\hline \multirow[t]{6}{*}{ Subcounty } & Ugunja & 57 & $23.7 \%$ \\
\hline & Alego & 39 & $16.2 \%$ \\
\hline & Gem & 27 & $11.2 \%$ \\
\hline & Ugenya & 53 & $22.0 \%$ \\
\hline & Rarieda & 31 & $19.9 \%$ \\
\hline & Bondo & 34 & $14.1 \%$ \\
\hline Which parent did you & Both parents & 47 & $19.4 \%$ \\
\hline \multirow[t]{2}{*}{ lose though death? } & Mother & 58 & $24.1 \%$ \\
\hline & Father & 136 & $56.5 \%$ \\
\hline Whom are you currently & Mother & 90 & $37.4 \%$ \\
\hline \multirow[t]{5}{*}{ living with? } & Father & 28 & $11.6 \%$ \\
\hline & Relative & 108 & $44.8 \%$ \\
\hline & Children's home & 5 & $2.1 \%$ \\
\hline & Guardian (not relative) & 9 & $3.7 \%$ \\
\hline & Other & 1 & $0.4 \%$ \\
\hline If you are living with a & Aunty/Uncle & 26 & $27.1 \%$ \\
\hline family/relative, what is the & Grandparent & 79 & $65.5 \%$ \\
\hline $\begin{array}{c}\text { relationship between you and } \\
\text { your caregiver? }\end{array}$ & Older sibling & 9 & $7.4 \%$ \\
\hline \multirow[t]{3}{*}{ How did your parent die? } & Sickness & 179 & $74.2 \%$ \\
\hline & Accident/Sudden & 33 & $13.6 \%$ \\
\hline & I don't know & 29 & $12.2 \%$ \\
\hline
\end{tabular}


The mean grief score at baseline was 32.77 and 31.32 for the experimental and control group respectively. These results show that the level of grief at baseline was largely equal for both groups, experimental $(M=32.77 \mathrm{SD} 7.55)$ and control group ( $M=31.32 \mathrm{SD}$ 8.64). At midline (week 12), the mean scores for both groups had reduced in both groups with experimental and control having means of $M=16.02$ (SD 9.89) and $M=30.52$, (SD 12.12). Finally, at the endline, (week $24)$, the mean scores for the groups were $(M=17.29, \mathrm{SD} 9.04)$ and $(M=30.87$, SD 10.99) for experimental and control groups respectively.

Table 3 shows the results of a paired-sample t-test statistics, comparing the means at baseline and midline. The mean difference between the midline CG scores and the baseline CG scores was statistically significant proving that the intervention was effective in reducing complicated grief symptoms $t(122)=$ $-15.79, p<0.001$. The exact difference in means was -16.75 , showing that the CG scores reduced by an average of 16.75 points after administering MCGT treatment in the experimental group. In the case of the control group, the paired sample test between the baseline and midline stage showed a statistically insignificant reduction of CG score among respondents by -0.79 points, $t(117)=$ $-0.712, p=0.478$. Showing that without treatment there was no significant change in complicated grief between the baseline and the midline stages.

To further determine the effect size of the intervention, a cohen's $d$ was calculated as follows as seen below. The results, $d=1.424$ showed that the intervention had a significantly large effect size $(>0.8)$.

$$
\begin{aligned}
& \text { Cohens } d=(M 2-M 1) / \mathrm{SD} \\
& d=(16.75) / 11.76=1.424
\end{aligned}
$$

In assessing the longevity of the treatment, participants were again assessed at the endline (12 weeks after the intervention was withdrawn). This assessment sought to determine if the effects of the treatment had changed significantly since the termination of the intervention. Table 4 shows the results of a paired t-test which showed that there was a marginal increase of 1.27 in the CG score between the midline stage and the endline stage in the experimental group though the increase was not statistically significant $\mathrm{t}(122)=1.550, p=0.124$. It can, therefore, the concluded that there was no statistically significant difference in the ICG scores between the midline stage and the endline stage. This result

Table 3. Paired samples test for mean difference of ICG scores at end of intervention (midline).

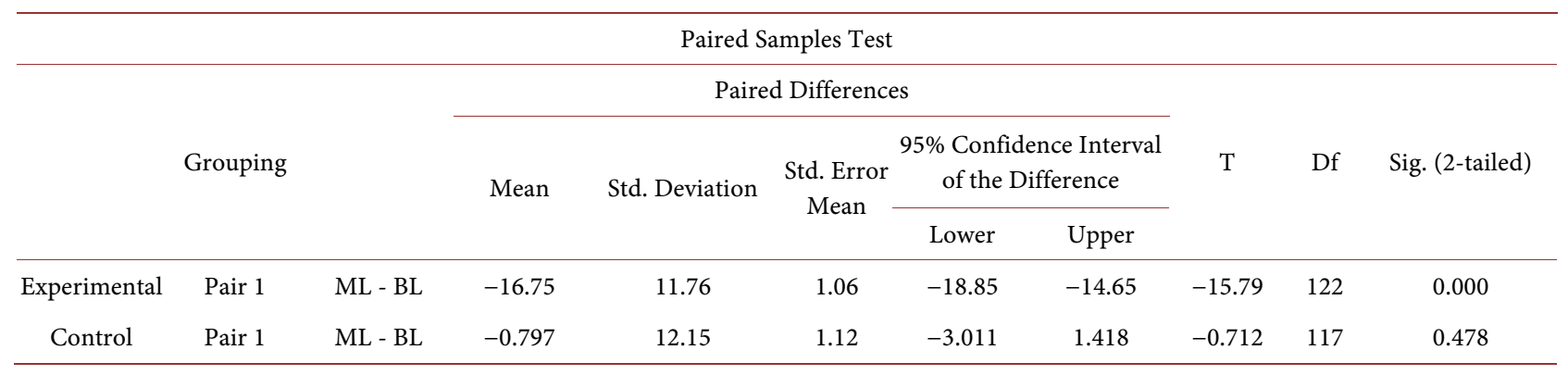

BL: Baseline; ML: Midline; EL: Endline. 
Table 4. Paired samples test for the mean difference of ICG scores at endline (12 weeks after intervention).

\begin{tabular}{|c|c|c|c|c|c|c|c|c|c|c|}
\hline \multicolumn{11}{|c|}{ Paired Samples Test } \\
\hline & \multirow{3}{*}{ Grouping } & & \multicolumn{5}{|c|}{ Paired Differences } & \multirow{3}{*}{$\mathrm{T}$} & \multirow{3}{*}{ df } & \multirow{3}{*}{$\begin{array}{c}\text { Sig. } \\
\text { (2-tailed) }\end{array}$} \\
\hline & & & \multirow{2}{*}{ Mean } & \multirow{2}{*}{ Std. Deviation } & \multirow{2}{*}{$\begin{array}{l}\text { Std. Error } \\
\text { Mean }\end{array}$} & \multicolumn{2}{|c|}{$\begin{array}{l}\text { 95\% Confidence Interval } \\
\text { of the Difference }\end{array}$} & & & \\
\hline & & & & & & Lower & Upper & & & \\
\hline Experimental & Pair 1 & EL - ML & 1.27 & 9.07 & 0.82 & -0.35 & 2.88 & 1.55 & 122 & 0.124 \\
\hline Control & Pair 1 & EL - ML & 0.35 & 12.78 & 1.18 & -1.98 & 2.68 & 0.29 & 117 & 0.768 \\
\hline
\end{tabular}

BL: Baseline; ML: Midline; EL: Endline.

means that the ICG score did not vary after the end of the MCGT treatment, thus indicating that the effect of the treatment continued to last after the intervention was ended.

A comparison between complicated grief scores for the midline and endline stages among the respondents in the control group also showed a statistically insignificant increase of 0.35 complicated grief points among the response. Indicating that there was no significant change in the ICG scores, $\mathrm{t}(117)=0.295, p=$ 0.768. It can, therefore, be inferred that without treatment.

\subsection{Effectiveness of MCGT Treatment by Age}

To test for the effectiveness of the MCGT tool by age, a paired-samples T-Test was used. Table 5 shows that for the paired sample test of changes in ICG scores by age, there was the reduction of complicated grief scores between baseline and endline stages for all the age groups in the experimental group of participants. Specifically, for the age group $10-11$ years, there was a statistically significant mean reduction of -19.63 at $\mathrm{t}(37)=-9.078, p<0.001$ in CG scores. In the age group $12-13$, the mean reduction was -16.10 at $\mathrm{t}(37)=-9.634, p<0.001$, while in the age group $14-15$ years, the reduction was -14.97 at $\mathrm{t}(30)=-8.299, p<$ 0.001. Indicating participants in all the age groups who underwent MCGT treatment had a significant reduction in their grief levels and did not have signs of complicated grief at the end of the therapy.

The same was not true for the participants in the control group as their mean scores remained above 25 indicating they were still having complicated grief. From the mean reductions in the CG scores by age groups, it was observed that for participants in all age groups, who went through the MCGT treatment, the CG scores significantly reduced by the end of the treatment.

\subsection{Effectiveness of MCGT Treatment by Nature of Death}

Three choices were available for the nature of death, these were sickness, accident and "I don't know". To check whether the MCGT treatment was effective regardless of the nature of the death of a parent. A paired-samples t-test was performed with the nature of death as a distinct group.

Table 6 presents results showing that, in all the three cases of the nature of 
Table 5. Paired samples test for the mean difference of ICG scores by age at baseline and endline.

\begin{tabular}{|c|c|c|c|c|c|c|c|c|c|c|}
\hline Paired & Samples & Test & & & & & & & & \\
\hline \multirow{3}{*}{ Grouping } & \multirow{3}{*}{ Age } & \multirow{3}{*}{ Group } & \multicolumn{5}{|c|}{ Paired Differences } & \multirow{3}{*}{$\mathrm{t}$} & \multirow{3}{*}{$\mathrm{df}$} & \multirow{3}{*}{$\begin{array}{c}\text { Sig. } \\
\text { (2-tailed) }\end{array}$} \\
\hline & & & \multirow{2}{*}{ Mean } & \multirow{2}{*}{ Std. Deviation } & \multirow{2}{*}{$\begin{array}{l}\text { Std. Error } \\
\text { Mean }\end{array}$} & \multicolumn{2}{|c|}{$\begin{array}{l}95 \% \text { Confidence Interval } \\
\text { of the Difference }\end{array}$} & & & \\
\hline & & & & & & Lower & Upper & & & \\
\hline \multirow{3}{*}{ Experimental } & $\begin{array}{c}10-11 \\
\text { (preteen) }\end{array}$ & $E L-B L$ & -19.63 & 13.33 & 2.16 & -24.01 & -15.25 & -9.07 & 37 & 0.000 \\
\hline & $\begin{array}{c}12-13 \\
\text { (early teen) }\end{array}$ & $E L-B L$ & -16.11 & 10.31 & 1.67 & -19.49 & -12.72 & -9.63 & 37 & 0.000 \\
\hline & $\begin{array}{c}14-15 \\
\text { (mid-teen) }\end{array}$ & EL - BL & -14.97 & 10.04 & 1.80 & -18.65 & -11.28 & -8.29 & 30 & 0.000 \\
\hline \multirow{3}{*}{ Control } & $\begin{array}{c}10-11 \\
\text { (preteen) }\end{array}$ & EL - BL & -6.09 & 9.634 & 1.65 & -9.45 & -2.73 & -3.69 & 33 & 0.001 \\
\hline & $\begin{array}{c}12-13 \\
\text { (early teen) }\end{array}$ & EL - BL & 2.03 & 11.47 & 1.91 & -1.85 & 5.91 & 1.061 & 35 & 0.296 \\
\hline & $\begin{array}{c}14-15 \\
\text { (mid-teen) }\end{array}$ & EL - BL & 0.00 & 9.33 & 1.91 & -3.94 & 3.94 & 0.000 & 23 & 1.000 \\
\hline
\end{tabular}

BL: Baseline; ML: Midline; EL: Endline.

Table 6. Paired samples test for the mean difference of ICG scores by nature of death at baseline and endline.

\begin{tabular}{|c|c|c|c|c|c|c|c|c|c|c|c|}
\hline \multirow{3}{*}{ Group } & \multirow{3}{*}{\multicolumn{3}{|c|}{ How did your parent die? }} & \multicolumn{5}{|c|}{ Paired Differences } & \multirow{3}{*}{$\mathrm{T}$} & \multirow{3}{*}{ Df } & \multirow{3}{*}{$\begin{array}{c}\text { Sig. } \\
\text { (2-tailed) }\end{array}$} \\
\hline & & & & \multirow{2}{*}{ Mean } & \multirow{2}{*}{$\begin{array}{c}\text { Std. } \\
\text { Deviation }\end{array}$} & \multirow{2}{*}{$\begin{array}{l}\text { Std. Error } \\
\text { Mean }\end{array}$} & \multicolumn{2}{|c|}{$\begin{array}{l}95 \% \text { Confidence Interval } \\
\text { of the Difference }\end{array}$} & & & \\
\hline & & & & & & & Lower & Upper & & & \\
\hline \multirow{3}{*}{ Experimental } & Sickness & Pair 1 & CG EL - CG BL & -16.47 & 11.78 & 1.34 & -19.14 & -13.79 & -12.27 & 76 & 0.000 \\
\hline & Accident & Pair 1 & CG EL - CG BL & -22.94 & 10.18 & 2.56 & -28.36 & -17.51 & -9.01 & 15 & 0.000 \\
\hline & I dont know & Pair 1 & CG EL- CG BL & -13.36 & 9.11 & 2.44 & -18.62 & -8.09 & -5.49 & 13 & 0.000 \\
\hline \multirow{3}{*}{ Control } & Sickness & Pair 1 & CG EL - CG BL & -1.25 & 11.62 & 1.39 & -4.04 & 1.54 & -0.891 & 68 & 0.376 \\
\hline & Accident & Pair 1 & CG EL - CG BL & -2.69 & 8.53 & 2.36 & -7.5 & 2.46 & -1.14 & 12 & 0.277 \\
\hline & I dont know & Pair 1 & CG EL - CG BL & -1.08 & 8.59 & 2.48 & -6.55 & 4.38 & -0.437 & 11 & 0.671 \\
\hline
\end{tabular}

BL: Baseline; ML: Midline; EL: Endline.

death, the respondents in the experimental group who went through the MCGT treatment, had a statistically significant reduction in their ICG scores, with the means in each case falling below, the cut of a score of 25. For the respondents whose parents died from sickness, there was a statistically significant reduction in the ICG scores -16.46 at $\mathrm{t}(76)=-12.26, p<0.001$. For the respondents whose parents died from an accident, there was a statistically significant reduction in the mean ICG scores of -22.94 at $\mathrm{t}(15)=-9.011, p<0.001$. Lastly, for the participants who did not know the nature of the death of their parents, the reduction in ICG scores was -13.357 at $\mathrm{t}(13)=-5.485, p<0.001$. On the other hand, for the participants in the control group, there was no statistically significant 
change in the mean ICG scores of the respondents on the basis of the nature of the death of their parents.

\section{Discussions}

The modification of the original 16 sessions Complicated Grief therapy was informed by recommendations from studies that had determined that the original CGT was very long, stringent and required rigorous training that would not be available in low-income areas or areas with limited mental health profession. The major modification was to reduce the number of sessions from 16 to 12 sessions removing 4 sessions that had techniques requiring special training. In addition, the assessment was only done after week 12 and then again at week 24 . Based on this, the main objective of this study was to confirm if this modified version would be effective in treating complicated grief within a school set up in rural Kenya.

To test for the effectiveness of the MCGT in the treatment of complicated grief, a paired samples T-Test was used. The results of a paired-sample t-test statistics, comparing the means at baseline and endline showed that the mean difference of CG scores between the baseline stage and the endline stage was -15.48 , which was a statistically significant reduction after administering the MCGT treatment. $\mathrm{t}(122)=-14.664, p<0.00$. To further determine the effect size of the intervention, a Cohen's $d$ was calculated resulting in $d=1.321$ which showed that the intervention had a significantly large effect size $(>0.8)$. Based on this result the average reduction of symptoms a week was 1.29 points.

The efficacy results echo those from other studies that have determined the effectiveness of the existing 16 sessions of complicated grief therapy. Pilot studies comparing CGT and Interpersonal therapy (IPT) in a randomized group of 83 adults who exhibited symptoms of complicated grief were conducted (Wetherell, 2012). The participants attended 16 sessions of individual therapy based on the CGT manual results showed that the CGT therapy showed $51 \%$ improvement compared to those who received IPT. In 2011, another study was done in Japan to test the efficacy of a modified CGT on women who were bereaved through violent death (Asukai et al., 2011). The aim of the study was to refine and modify the original CGT manual for the Japanese population and to confirm its efficacy on traumatic grief. Thirteen Japanese women who exhibited PTSD resulting from traumatic grief were taken through 12 - 16 weeks of the modified CGT program. Specifically, $46 \%$ of participants showed change based on Jacobson's Reliable Change Index (Asukai et al., 2011).

Efficacy studies have largely been focused on elder bereaved persons, in 2014, in New York, a total of 151 individuals 50 years and above were recruited in a cohort study to determine the efficacy of CGT in comparison to IPT. The participants had a minimum score of 30 on the ICG. The participants were assessed at baseline and at intervals of $8,12,16$ and finally at 20 weeks. CGT had a way better treatment outcomes with an average reduction of 1.05 ICG points per 
week [t633 $=3.85 ; p<0.001]$ ) (Shear et al., 2014).

In this current study, the average reduction of scores per week was 1.29, meaning that the modified version of CGT which was tested among orphans in Siaya county, and which lasted only 12 weeks recorded higher reduction than the current 16 session CGT which had an average weekly reduction of 1.05 . There were no studies found that have tested CGT among orphaned children and neither were there studies found that have tested CGT intervention in the Kenyan context.

The results confirmed that MCGT was very effective in the reduction of complicated grief symptoms and was found to be effective for all participants regardless of age with a slightly higher reduction seen among younger participants. MCGT was also found to be more effective among participants who had experienced sudden parental death such as accidents.

\section{Conclusion and Recommendations}

Ideally, normal grief does not need clinical intervention; however, sometimes acute grief can become a chronic incapacitating condition called complicated grief. The results presented in this paper show that orphaned children are a high-risk population when it comes to the development of complicated grief. Prolonged sickness and caring for a sick parent have been shown to increase the chances of development of complicated grief and the fact that many of the orphans in this study had lost a parent through sickness, justifies the high prevalence of complicated grief.

Based on the findings from this study confirming the effectiveness of the treatment as a school-based program, more griefwork based on this intervention can be adopted in schools especially in high-risks areas such as those with a high number of orphans. Specifically, it is recommended that, since existing policies in Kenya do not provide any specific grief work program for orphaned children, these policy gaps in the current psychosocial care and support frameworks for orphans can be addressed by adopting this MCGT intervention as a grief work program for schools and institutionalized care.

There is a need for the government and especially children's service and welfare departments to consider having policies to enhance the adoption of such programs and ensuring all school counselors are trained on MCGT. This could assist to ensure timely intervention for bereaved children presenting with complicated grief. The adoption of this MCGT could also provide training grounds for professional bodies in counseling to train school counselors and increase their competence in grief management.

The limitations of this study were; first, the study had a limited geographical scope in that the study site was selected purposively due to the high HIV prevalence in the Siaya county. To validate the results on the effectiveness of MCGT, there may be needed to conduct further studies testing the efficacy of MCGT using a randomized national representative sample. A second limitation for this 
study was the language barrier. This study was conducted in English and one of the inclusion criteria was the ability of the child to understand the tools used in the screening, diagnosis, and intervention. It is therefore recommended that for these tools to cover a larger number of orphaned children in need of grief intervention, there may be the need for studies to test the reliability and validity of the ICG tool translated versions in local languages.

\section{Conflicts of Interest}

The authors declare no conflicts of interest regarding the publication of this paper.

\section{References}

Akerman, R., \& Statham, J. (2014). Bereavement in Childhood: The Impact on Psychological and Educational Outcomes and the Effectiveness of Support Services. Childhood Wellbeing Research Centre.

http://www.cwrc.ac.uk/news/documents/Revised_Childhood_Bereavement review 20 14a.pdf

Asukai, N., Tsuruta, N., \& Saito, A. (2011). Pilot Study on Traumatic Grief Treatment Program for Japanese Women Bereaved by Violent Death. Journal of Traumatic Stress, 24, 470-473. https://doi.org/10.1002/jts.20662

Enez, Ö. (2018). Complicated Grief: Epidemiology, Clinical Features, Assessment and Diagnosis. Psikiyatride Guncel Yaklasimlar-Current Approaches in Psychiatry, 10, 269-279. https://doi.org/10.18863/pgy.358110

Handa, S., Halpern, C. T., Pettifor, A., \& Thirumurthy, H. (2014). The Government of Kenya's Cash Transfer Program Reduces the Risk of Sexual Debut among Young People Age 15-25. PLoS ONE, 9, e85473. https://doi.org/10.1371/journal.pone.0085473

Huyah, H. V. (2017). Factors Affecting Psychological Well Being of Orphans and Separated Children in Five Low and Middle Income Countries. Which Is More Important Quality or Form of Care? Florence, SC: Clemson University.

http://tigerprints.clemson.edu/cgi/viewcontent.cgi?article=2910\&context=all dissertati ons

Kersting, A., Brähler, E., Glaesmer, H., \& Wagner, B. (2011). Prevalence of Complicated Grief in a Representative Population-Based Sample. Journal of Affective Disorders, 131, 339-343. https://doi.org/10.1016/j.jad.2010.11.032

Koon, O., \& Neo, P. (2016). Complicated Grief: An Introduction to Current Literature and Management Strategies in Home Hospice Care. Nursing and Palliative Care, 1. https://doi.org/10.15761/NPC.1000135

Ministry of Labour Social Security and Services, Kenya \& Department of Children Services Kenya (2015). National Psychosocial Support Guidelines for Orphans and Vulnerable Children in Kenya.

https://www.usaidassist.org/sites/default/files/pss guidelines 004.pdf

Mwoma, T., \& Pillay, J. (2015). Psychosocial Support for Orphans and Vulnerable Children in Public Primary Schools: Challenges and Intervention Strategies. South African Journal of Education, 35, 1-9. https://doi.org/10.15700/saje.v35n3a1092

Papa, A., Rummel, C., Garrison-Diehn, C., \& Sewell, M. T. (2013). Behavioral Activation for Pathological Grief. Death Studies, 37, 913-936.

https://doi.org/10.1080/07481187.2012.692459 
Prigerson, H. G., Maciejewski, P. K., Reynolds, C. F., Bierhals, A. J., Newsom, J. T., Fasiczka, A., Frank, E., Doman, J., \& Miller, M. (1995). Inventory of Complicated Grief: A Scale to Measure Maladaptive Symptoms of Loss. Psychiatry Research, 59, 65-79. https://doi.org/10.1016/0165-1781(95)02757-2

Selamu, L. G., \& Singhe, M. (2018). Access to Mental Health Care Services for the Orphan and Vulnerable Children in Addis Ababa Ethiopia. American Journal of Applied Psychology, 7, 11-13. https://doi.org/10.11648/j.ajap.20180701.12

Shear, M. K., Wang, Y., Skritskaya, N., Duan, N., Mauro, C., \& Ghesquiere, A. (2014). Treatment of Complicated Grief in Elderly Persons: A Randomized Clinical Trial. JAMA Psychiatry, 71, 1287-1295. https://doi.org/10.1001/jamapsychiatry.2014.1242

Simon, N. (2013). Treating Complicated Grief. The Journal of the American Medical Association, 310, 416. https://doi.org/10.1001/jama.2013.8614

Skeen, S. A., Sherr, L., Croome, N., Gandhi, N., Roberts, K. J., Macedo, A., \& Tomlinson, M. (2017). Interventions to Improve Psychosocial Well-Being for Children Affected by HIV and AIDS: A Systematic Review. Vulnerable Children and Youth Studies, 12, 91-116. https://doi.org/10.1080/17450128.2016.1276656

Solomon, C. G. (2015). Complicated Grief. New England Journal of Medicine, 372, 153-160. https://doi.org/10.1056/NEJMcp1315618

SOS (2017). Children's Statistics. SOS-US-EN. https://www.sos-usa.org/Our-Impact/Focus-Areas/Advocacy-Movement-Building/Chil dren-s-Statistics

State Department of Social Protection (2011). OVC Secretariat. http://labour.go.ke/ovcsecretariat.html

Stroebe, M., \& Schut, H. (1999). The Dual Process Model of Coping with Bereavement: Rationale and Description. Death Studies, 23, 197-224. https://doi.org/10.1080/074811899201046

Tol, W. A., Komproe, I. H., Susanty, D., Jordans, M. J. D., Macy, R. D., \& De Jong, J. T. V. M. (2008). School-Based Mental Health Intervention for Children Affected by Political Violence in Indonesia: A Cluster Randomized Trial. The Journal of the American Medical Association, 300, 655. https://doi.org/10.1001/jama.300.6.655

UNAIDS (2018). 2017 Global HIV Statistics. http://www.unaids.org/sites/default/files/media asset/UNAIDS FactSheet en.pdf

Wagner, B., \& Maercker, A. (2010). The Diagnosis of Complicated Grief as a Mental Disorder: A Critical Appraisal. Psychologica Belgica, 50, 27. https://doi.org/10.5334/pb-50-1-2-27

Wetherell, J. L. (2012). Complicated Grief Therapy as a New Treatment Approach. Dialogues in Clinical Neuroscience, 14, 159-166.

World Orphans (2018). Why Orphans? World Orphans. https://www.worldorphans.org/why-orphans/ 


\section{Annex Sociodemographic Questionnaire}

\section{SOCIODEMOGRAPHIC QUESTIONNAIRE ON COMPLICATED GRIEF AMONG ORPHANED CHILDREN IN PRIMARY SCHOOLS IN SIAYA COUNTY, KENYA}

\section{DATE:}

CODE:

My name is Maureen Adhiambo Onyango, a PhD student in Clinical Psychology at Daystar University. This study aims to understand the prevalence of grief and to support in managing the consequences of grief among orphans in primary schools in Kenya. This information is confidential and will help in determining if you may be having problems coping with the loss of your parent(s). Please read carefully and tick $(\sqrt{ })$ where applicable or write the response as required.

INTERVIEWER:

Part A: BIODATA

1. Name of School

2. Gender: Male $\square \quad$ Female

3. Age (years)
$10 \square$
11
12
13
14
15

4. Religion

Catholic

Anglican

Pentecostal

Adventist

Muslim

Other

5. I am in class

Class $3 \square$

Class 4

Class $5 \square$

Class $6 \square$

Class 7

6. How many siblings do you have?

One $\square \quad$ Two $\square \quad$ Three $\square \quad$ Four and above

\section{PART B: NATURE OF ORPHANHOOD/OTHER LOSSES/NATURE OF DEATH}

The following questions will ask you more about the death of your parent, more information about how they died, and if you have lost any other loved one

7. Have you lost a parent through death?
YES $\square$
NO $\square$

8. If YES in 7, which parent did you lose through death?
Both Parents
Mother
Father $\square$

9. In which year did your mother die?
$2018 \square \quad \square 017$
2016
10. In which year did your father die?
2015
2014 and below
Alive
2018
2017
2016
2014 and below
Alive

11. How close was your relationship with your mother? (if mother dead)
Not close $\square$
A bit close $\square$
Very close $\square$

12. How close was your relationship with your father (if father is dead)?
Not close
Somewhat close $\square$
Very close

13. How close are you with the surviving parent?

Not close $\square \quad$ Somewhat close

14. How did your parent die?
Sickness
Accident/Sudden

Very close

Both dead

15. Was your parent sick before they died?

YES $\square \quad$ NO $\square$

16. Did you take care of your parent when they were sick?

YES $\square \quad$ NO $\square$

17. Were you with your parent when he/she died?

YES $\square \quad$ NO $\square$

18. Where did your parent die?

at home $\square \quad$ in the hospital $\square \quad$ I do not Know $\square \quad$ Other $\square$

19. Apart from your parent, have you ever lost another loved one?

YES $\square \quad$ NO $\square$

20. If YES in 19 above, which other loved one have you lost?

Sibling $\square \quad$ Friend $\square \quad$ Other close relative 


\section{Continued}

\section{PART C: AVAILABILITY OF CAREGIVER/}

This section seeks to find out who you are currently living with and the nature of relationship with the current care giver

21. Whom are you currently living with?
Mother $\square$
Father Relative $\square$
Children's Home
Guardian (not relative)

22. Do you currently live with any of your brothers or sisters?

YES $\square \quad$ NO $\square$

23. If not living with your other siblings. How often do you see your sisters/brothers?
Never $\square \quad$ Rarely (yearly)
Few times (monthly)
Frequently(daily/weekly)

24. If you are living with a family member/relative, what is the relationship between you and your caregiver? Aunty/Uncle $\square$ Grandparent $\square \quad$ Older Sibling

25. If living with a Guardian who is not a relative, who are they?
Neighbor $\square$ Teacher $\square$
Pastor
Friend to parent

26. If living in a children's home, who took you there

Relative $\square$ Teacher/School $\square \quad$ Relative $\square \quad$ Pastor $\square \quad$ Guardian (not relative)

PART D: CULTURE AND DEATH

This section seeks to understand some of the cultural practices surrounding death and how they affected you

27. Did anybody tell you that your parent had died?

YES $\square \quad$ NO $\square$

28. If YES in 27 above, who informed you about the death of your mother/father
Surviving Parent
Siblings
Other relative $\square \quad$ Teacher
Pastor $\square$

29. If NO in 27 above, how did you know about the death?

I was there when he/she died

I saw/heard people crying over the death

30. Did you attend the burial of your parent?

YES $\square \quad$ NO $\square$

31. Did anyone tell/ask you to view the body in the coffin?

YES $\square \quad$ NO $\square$

32. Did you view the body in the coffin?

YES $\square \quad$ NO $\square$

33. During the preparation for burial, which of the following activities bothered you most (Tick at least TWO)

Screams/Wails and Cries $\square$

Many people in your home cooking and eating

The night dancing/music $\square$

Having the body in the house all night on the day before the burial

Viewing the body $\square$

34. After the burial which of the following activities bothered you most (Tick as appropriate)

The night dancing/music $\square$

Empty compound in the next days

Relatives coming to share out your parents belongings

\section{PART E: PSYCHOSOCIAL SUPPORT}

This section seeks to find out if you received any emotional support at the time of death, burial and after burial of your parent

35. Did anyone talk/comfort you on how you were feeling about the death of your parent?

YES $\square \quad$ NO $\square$

36. Did you receive any counseling/talk about meaning of death?

YES $\square$ NO $\square$

37. If YES in 36 above, from whom did you receive this talk?

Relative $\square \quad$ Pastor $\square \quad$ Teacher

38. Did you receive any guidance and counseling in school when you returned back to school after the burial?

YES $\square \quad$ NO $\square$

39. When you feel sad in school do you have someone you can talk to?

YES

NO $\square$

PART F: THOUGHTS/BELIEFS 


\section{Continued}

The following questions seek to understand what you thoughts in relation to the death of your parent

40. Do you still think your parent will come back? YES $\square \quad$ NO $\square$

41. Since your parent died, have you had thoughts that your loved one did not have to die? YES $\square$ NO $\square$

42. Since your parent died, have you had thoughts that life is unbearable without them? YES $\square \quad$ NO $\square$

43. Since your parent died, have you had thoughts that the only thing that can really help you is to have this person back? YES $\square \quad$ NO $\square$

44. Since your parent died, have you had thoughts that you could have done something to stop the death? YES NO

45. Since your parent died, have you had thoughts that relatives/doctors did not do enough to stop the death? YES $\square$ NO $\square$

46. Since your parent died, have you had thoughts that you have no one to turn now that your loved one is gone? YES NO $\square$

47. Since your parent died, have you had thoughts that something is wrong with you because you are grieving so much? You should be over this by now? YES NO

\section{PART I: ACADEMIC PERFORMANCE/SCHOOL ATTENDANCE}

The next questions will ask you about your school life in terms of school attendance and academic performance

48. Did any of your teachers attend the burial of your parent?

YES $\square$ NO $\square$

49. After the burial how long did you stay without going to school?

Less than two weeks

More than a month

A whole term $\square$

More than one term

50. Since your parent died have you had to miss school?

YES $\square \quad$ NO $\square$

51. If YES why did you miss school

Lack of school fee

Lack of school items (uniform, books, pencils).

Chores at home

Sickness

Discipline issues

Others

52. Compared to the time before your parent died do you feel your performance in school has reduced? YES $\square \quad$ NO

53. If yes above, what is causing the reduction in performance?

I am not able to concentrate in class or to read

I am worried about my future and/or that of my siblings

I have no interest in reading anymore

54. Which of these factors could also contribute to your drop in performance?

I am absent from school a number of times

At home I have no time to read due to house chores

I lack school items such as books, stationeries

THE END: THANKYOU FOR PARTICIPATING

MAUREEN A ONYANGO-PRINCIPAL RESEARCHER 